\title{
Research Paper: Relationship Between Using Television and Behavioral Problems of Pre-School Children
}

\author{
Mansooreh Asghari', Mansoureh Karimzadeh ${ }^{1,2 *}$, Robab Teymouri $^{2}$ \\ 1. Department of Preschool Education, University of Social Welfare and Rehabilitation Sciences, Tehran, Iran. \\ 2. Pediatric Neurorehabilitation Research Center, University of Social Welfare and Rehabilitation Sciences, Tehran, Iran.
}

\section{Article info:}

Received: 12 May 2017

Accepted: 09 Aug. 2017

\section{Keywords:}

Games, Using television, Behavioral problems ditation: Asghari M, Karimzadeh M, Teymouri R. Relationship Between Using of Television and Behavioral Problems of Pre-School Children. Iranian Rehabilitation Journal. 2017; 15(4):325-332. https://doi.org/10.29252/nrip.irj.15.4.325

https://doi.org/10.29252/nrip.irj.15.4.325

\section{ABSTRACT}

Objectives: The aim of the present study was to evaluate the relationship between the use of television and behavioral problems in children.

Methods: This is a descriptive and correlational research. The statistical population of the study included 4- to 6-year-old pre-school children in Tehran who were selected using multistage cluster sampling. A sample of 150 children was selected. The subjects responded to two questionnaires of Rutter's behavioral problems and a researcher-made questionnaire on the extent of using electronic devices. Data were analyzed using SPSS 22 software in two sections: descriptive (tables and diagrams) and inferential statistics (univariate and multivariate analysis of variance and one-way and two-way Chi-square tests).

Results: The findings showed that there was a relationship between the use of television with isolation and anxiety in 4- to 6-year-old children. There was no significant relationship between having a personal computer and the time spent in watching television, but overall, the percentages of the total results indicated that children who did not have computers spent more hours watching television. Further, there was no significant relationship between the number of hours spent for playing with children and the time spent for watching television, but the results represented that children who played more than 2 hours spent less time watching television. However, there was a significant difference in aggressive behavior, neglect and childish behavior, but no significant difference in isolation and anxiety between children watching foreign movies and cartoons and those who watched Iranian movies and cartoons.

Discussion: It seems that decreasing children's television watching can prevent behavioral problems.

\footnotetext{
* Corresponding Author:

Address: Pediatric Neurorehabilitation Research Center, University of Social Welfare and Rehabilitation Sciences, Tehran, Iran. Tel: +98 (21) 22180083-92

E-mail: mkarimz2000@gmail.com
} 


\section{Introduction}

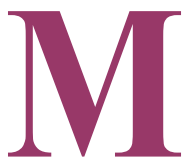

edia includes anything that carries a message or meaning to a recipient. Mass communication (radio, television, newspapers, magazines, and various print and electronic media) that affects a large number of audiences can be used for the practical meaning of media. One such media is the television, which is a communication system for broadcasting and receiving moving pictures and sounds at a distance [1].

At first glance, the recent developments in the television industry seem to be very satisfactory. Films and entertainment programs can be received at the push of a button from around the world at any time of day. However, this is associated with many deep concerns such as extremely easy access to inappropriate programs, especially in the case of children and minors. The volume of violence scenes in media has increased along with the increasing number and variety of media [2]. In general, media shows a world where unhealthy behaviors such as physical violence, unprotected sexual behavior, smoking, and drinking intoxicants seem safe [3]. Hopf et al. [4] concluded that most children who watched violent horror movies in their childhood and adolescents who played violent games exhibited more violence and crime at the age of 14 years. Also, another research showed that violent content in most of the media has a small but significant effect in the real world such as learning aggressive behavior, decreased sensitivity, and causing fear [5].

Children are among the main viewers of television. The effect of these media programs on various social, cultural, and psychological aspects of children is undeniable. Children perceive things differently than adults due to the lack of sufficient experience and cognitive features that are specific to their developmental level [6]. Living in today's world has created a situation where television is one of the pillars of families, and this pillar can play a lot of roles among peers in terms of stimulating imagination. This non-interactive messenger is forced into the lives of people in several ways even when a scientific and organized effort is not used to attract audience and as such, children should be considered [7]. Television can be a double-edged sword; it can be effective in forming a prosperous future for children with awareness, education and social knowledge and can also lead to antisocial problems such as poor training, mental destruction, as well as decline. It seems that factors such as family, peer group, educational environments, and the media itself play a major role in children being influenced by television. These factors can inhibit or amplify the harmful effects of television. This will consequently affect the behavior, deed, and even thoughts of children towards television.

Based on Bandura's social learning theory [8], children learn their cognitive and social skills by observing the performance of those around. Similarly, they also learn to be aggressive by watching violence in the media. There are several important points to note from the aforementioned theory: first, a person may model aggressive behaviors without any reinforcement even if it emerges (latent learning); and second, a person does not have to be personally rewarded to learn aggressive behavior. Tannenbaum [9] pointed out in his arousal hypothesis that facing media violence increases aggression due to visitors' stimulation. Similarly, the desensitization hypothesis [10] stated that constant watching of violence on television will result in reduced emotional response to violence in television. The disinhibition hypothesis $[11,12]$ stated that people who are forbidden from aggressive behavior with training and experience will lose their inhibition of aggressive actions by watching a lot of violence on television.

The Gerbner's Cultivation Theory stated that reality watched through television affects beliefs and consequently, the behavior of viewers [13]. Further, the theory of cultivation stated that there are attitudes as "cultivating" in watching too much television, as it is more harmonious with a world portrayed by television programs than the real world. This theory referred to the cumulative and dense process in which the use of television rears beliefs and convictions about social reality [14, 15]. In addition, several cultivating theorists argued that television has long-term, gradual, indirect but dense and accumulated effects. They emphasized that watching television has more attitudinal effects than behavioral effects $[14,16-18]$. The use and gratification theory is based on the concept of audience activity, which means voluntary orientation of audiences in the selection of media, and refers to motivation based on needs and goals stated by the audience $[19,20]$.

Studies have shown that even infants watch television for half hour, and children aged 4-6 years watch television for 2.5 hours and 6-8 hours on holidays. Also, onethird of 7-year-old children spend 4 hours a day watching television, and only $10 \%$ of children have never watched television. Primary school children spend 1460 hours a year watching television. In contrast, they have less than 1000 hours of school training, and each family annually spends about 4000 hours watching television program, which has reached to 100000 hours in the late $20^{\text {th }}$ century [21]. Children in the age group of $7-17$ years 
spend 25 hours per week watching television. Moreover, $20 \%$ of 2 - to 7 -year-old children, $46 \%$ of 8 - to 12 -yearold children and $56 \%$ of 13 - to 17 -year-old teens have private television in their room.

Studies have also reported that 15 to $22 \%$ of children need treatment interventions and 70 to $80 \%$ do not receive appropriate intervention for their behavioral problems. Behavioral problems begin in the early years of primary school children and reach the peak at 8 to 15 years of age [22]. In a study by Gilson (2003), it was concluded that children who watch television a lot (most of the day) have higher behavioral disorders, anxiety, depression, and aggression. The findings of Ozmert [23] on behavioral problems caused by watching too much television revealed that problems such as isolation, social problems, attention problems, thought problems, delinquent behavior, and aggressive behavior are positively correlated with the amount of time spent in television watching. In a study by Garvis and Pendergast [24], it was pointed out that television is used in families as educator and babysitter and is also used in motivating children's physical exercise.

In addition, families also believe education programs on television to be positive. Juncal Cunado et de Gracia [25] concluded that those who spend only one to two hours watching television reported a higher level of happiness than those who spend more time watching television. Naghdi Do Robati [26] concluded that pre-school education does not affect children's social adaptability. Esmi et al. [27] concluded that there is a positive relationship between watching commercials and the use of feed, accessories, and service facilities in that they significantly increase the adherence of children and adolescents to recreational and saving behavior, safety issues, and traffic regulations. The results of Seyedamini et al.'s study [28] indicate that there was no significant relationship between the behavior of primary school children and watching television a lot; however, there was a significant positive correlation with childhood obesity.

It seems that excessive use of television by children can affect their psychological behaviors and may later require rehabilitation and psychological interventions. Hence, the prevention of these behaviors may be closely linked to the extreme watching of television. The aim of the present study was to evaluate the relationship between the use of television and behavioral problems in children.

\section{Methods}

This is an ex-post facto descriptive study. The population of this research included all 4- to 6-year-old pre-school children in Tehran educational districts in 2014/2015 academic year. The multistage cluster sampling method was used for sampling. The sample size was determined to be 150 using Cochran's method.

$$
n=\frac{\frac{Z^{2} p q}{d^{2}}}{1+\frac{1}{N}\left(\frac{Z^{2} p q}{d^{2}}-1\right)}
$$

In general, 150 pre-school children were selected in the first stage from 19 educational districts of Tehran, and three kindergartens were selected in the second stage from three educational districts using the same method. The samples were divided into three groups with 50 samples obtained from three educational districts: A. profited (Educational District 2); B. semi-profited (Educational District 6); and C. non-profited (Educational District 19). Data were obtained using two methods, namely library and field research methods. After referring to library, websites, related books and theses, data were collected using two standard questionnaires: 1. Behavioral problems of preschool children questionnaires [29], and 2. a made-researcher questionnaire. Parents were asked to fill out the two questionnaires after coordination with official authorities.

The reliability of behavioral problems questionnaire using Cronbach's alpha for the three components, i.e., aggression, neglect and childish behaviors, and isolation and anxiety, was obtained as $0.86,0.79$, and 0.84 , respectively. Also, the internal consistency was obtained as 0.83 . In the researcher-made questionnaire "Time spent for electronic devices," the reliability of this test was obtained as 0.78 using Cronbach's alpha for the whole questionnaire. In this research, based on the nature of the variables and hypotheses, data were analyzed using SPSS 22 software through univariate and Multivariate Analysis of Variance (MANOVA) and one-way and twoway Chi-square tests. All ethical considerations while implementing the research were considered in accordance with international guidelines and were approved by Ethics Committee of the University of Social Welfare and Rehabilitation Sciences.

\section{Results}

Children's behavioral problems comprised three components: aggression, neglect and childish behaviors, and isolation and anxiety. Multivariate analysis of variance was used to evaluate this hypothesis that there was a significant difference between three groups of children watching television for about 2 hours, 2 to 4 hours, and 
Table 1. The results of the three groups based on three elements of Children's Behaviour Questionnaire

\begin{tabular}{ccccccccc}
\hline \multirow{2}{*}{ Variable } & \multicolumn{2}{c}{ Aggression } & \multicolumn{2}{c}{ Neglect and Childish Behaviors } & \multicolumn{2}{c}{ Isolation and Anxiety } \\
\cline { 2 - 8 } & $\mathbf{M}$ & SD & M & SD & M & SD & Number \\
\hline $2 \mathrm{~h}$ & 0.66 & 0.31 & 0.52 & 0.34 & 0.29 & 0.25 & 72 \\
\hline $4 \mathrm{~h}$ & 0.67 & 0.34 & 0.56 & 0.34 & 0.41 & 0.26 & 51 \\
\hline $4 \mathrm{~h}$ & 0.73 & 0.34 & 0.58 & 0.30 & 0.65 & 0.35 & 27 \\
\hline
\end{tabular}

Note: M: Mean; SD: Standard Deviation

Mranlan RehabullatonDourna

Table 2. ANOVA test results

\begin{tabular}{ccccccc}
\hline Source of Effect & Variable & SS & df & MS & F & P \\
\hline \multirow{2}{*}{ Year } & Aggression & 0.08 & 2 & 0.04 & 0.39 & 0.68 \\
& Neglect and childish behavior & 0.08 & 2 & 0.04 & 0.38 & 0.69 \\
& Isolation and anxiety & 2.57 & 2 & 1.29 & 16.90 & 0.01 \\
Error & Aggression & 15.52 & 147 & 0.11 & \\
& Neglect and childish behavior & 16.42 & 147 & 0.11 \\
\hline
\end{tabular}

more than 4 hours. The results of the descriptive indicators and assumptions of this test are shown in Table 1.

The variance difference among the three groups showed that there was no significant difference among variances of aggression $(\mathrm{F} 2.147=0.74, \mathrm{P}=0.48)$, neglect and the childish behavior of children $(\mathrm{F} 2.147=0.50, \mathrm{P}=0.60)$, and isolation and anxiety $(\mathrm{F} 2.147=2.49, \mathrm{P}=0.08)$. The homogeneity of variance among groups was performed by Levene's test.

The assumption of homogeneity of covariance matrix $\left(\mathrm{M}_{\text {box }}=24.24\right.$, F12.32965.93=1.95, $\left.\mathrm{P}=0.07\right)$ also confirmed this assumption. The results of the multivariate Wilks' Lambda test with a value of 0.80, F60.2900 $=6.63$, and $\mathrm{P}=0.001$ showed that there was a significant difference in behavioral problems between the three groups.

The univariate analysis of variance confirmed the results obtained from the multivariate analysis of variance, which showed that there was no significant difference between two groups, aggression (F2.1470.39, $\mathrm{P}=0.68)$ and neglect and childish behavior of children (F2.147 $=0.38$, $\mathrm{P}=0.69)$, but a significant difference was observed in isolation and anxiety $(\mathrm{F} 2.147=16.90, \mathrm{P}=0.01)$ (Table 2).

In this study, after determining the significant difference among the three groups in isolation and anxiety, the LSD post hoc test was used to determine which group is responsible for this difference. The obtained results

Table 3. Chi square test for the relationship between having personal computer and watching TV

\begin{tabular}{|c|c|c|c|c|}
\hline Computer Ownership & Index & Not at All & 2 to 4 Hours & $>4$ Hours \\
\hline \multirow{3}{*}{ Not having personal compute } & Frequency & 55 & 45 & 19 \\
\hline & & & & \\
\hline & Percentage & 76.39 & 90 & 70.37 \\
\hline \multirow{3}{*}{ Having personal computer } & Frequency & 17 & 5 & 8 \\
\hline & & & & \\
\hline & Percentage & 23.61 & 10 & 29.63 \\
\hline
\end{tabular}


Table 4. Chi square test results for the relationship between the number of hours for playing with children and time spent watching TV

\begin{tabular}{|c|c|c|c|c|}
\hline Hours of Playing With Child & Index & Not at All & 2 to $4 \mathrm{~h}$ & More Than 4 Hours \\
\hline \multirow{2}{*}{$2 \mathrm{~h}$} & Frequency & 54 & 36 & 16 \\
\hline & Percentage & 75 & 70.59 & 59.26 \\
\hline \multirow[t]{2}{*}{ More than $2 \mathrm{~h}$} & Frequency & 18 & 15 & 11 \\
\hline & Percentage & 25 & 29.41 & 40.74 \\
\hline
\end{tabular}

Table 5. The behavioral problems among children watching Iranian and foreign movies and cartoons

\begin{tabular}{|c|c|c|c|c|c|c|c|}
\hline \multirow{2}{*}{ Variable } & \multicolumn{2}{|c|}{ Aggression } & \multicolumn{2}{|c|}{ Neglect and Childish Behavior } & \multicolumn{2}{|c|}{ Isolation and Anxiety } & \multirow{2}{*}{ Number } \\
\hline & $\mathbf{M}$ & SD & $M$ & SD & M & SD & \\
\hline Foreign & 0.75 & 0.34 & 0.61 & 0.28 & 0.40 & 0.29 & 82 \\
\hline Iranian & 0.60 & 0.29 & 0.47 & 0.38 & 0.40 & 0.33 & 63 \\
\hline
\end{tabular}

showed that the children watching television for 2 hours are less isolated and anxious than the ones who watch television for more than 2 hours a day.

The results of the Chi-square test, which evaluated the relationship between having personal computer and the time spent for watching television, showed that there was no significant relationship $\mathrm{X}^{2}=5.27, \mathrm{df}=2, \mathrm{P}=0.07$ ). But the obtained percentages indicated that children who did not have any computers spent more hours watching television (Table 3). The Chi-square test, which evaluated the relationship between the hours that parents played with children and the time spent for watching television, showed that there was no significant relationship $\mathrm{X}^{2}=2.34, \mathrm{df}=2, \mathrm{P}=0.30$ ). But the percentages of the entire results indicated that children who spent more hours playing spent less time watching television (Table 4).
Multivariate analysis of variance was used to evaluate the aforementioned hypothesis. The descriptive indicators and assumptions of this test are shown in Table 5. Evaluation of variance difference among the three groups showed that there was no significant difference in variances of aggression $(\mathrm{F} 1.143=0.53, \mathrm{P}=0.47)$, neglect and childish behavior of children $(\mathrm{F} 1.143=3.27, \mathrm{P}=0.05)$, and isolation and anxiety $(\mathrm{F} 1.143=0.99, \mathrm{P}=0.32)$. The homogeneity of variance among groups was performed by Levene's test.

The assumption of homogeneity of covariance matrix (F6.123992.47=2.39, $\mathrm{M}_{\text {box }}=14.63, \mathrm{P}=0.05$ ) also confirmed this assumption. After confirming the assumptions of multivariate analysis of variance, the results of multivariate Wilks' Lambda test with a value of 0.92 , $\mathrm{F} 3.141=4.00$ and $\mathrm{P}=0.01$ showed that there was a sig-

Table 6. Analysis of one-way variance

\begin{tabular}{|c|c|c|c|c|c|c|}
\hline Source of Effect & Variable & SS & df & MS & $\mathbf{F}$ & $\mathbf{P}$ \\
\hline & Aggression & 0.81 & 1 & 0.81 & 8.06 & 0.01 \\
\hline \multirow[t]{3}{*}{ Year } & Neglect and childish behavior & 0.65 & 1 & 0.65 & 6.06 & 0.02 \\
\hline & Isolation and anxiety & 0.01 & 1 & 0.01 & 0.001 & 0.98 \\
\hline & Aggression & 14.33 & 143 & 0.10 & & \\
\hline \multirow[t]{2}{*}{ Error } & Neglect and childish behavior & 15.36 & 143 & 0.11 & & \\
\hline & Isolation and anxiety & 13.26 & 143 & 0.09 & & \\
\hline
\end{tabular}


nificant difference in behavioral problems among the three groups.

The univariate analysis of variance confirmed the results obtained from the multivariate analysis of variance, which showed that there was a significant difference between two groups, aggression (F2.146=8.06, $\mathrm{P}=0.01$ ), neglect and the childish behavior $(\mathrm{F} 2.146=6.06, \mathrm{P}=0.02)$, but there was no significant difference in isolation and anxiety $(\mathrm{F} 2.146=0.001, \mathrm{P}=0.98)$ (Table 6). The obtained means showed that the group of children who watch foreign movies and cartoons had more aggression, neglect and childish behavior.

\section{Discussion}

The results of this study showed that there was a significant difference among the three groups of children watching television for 2 hours, 4 hours, and more hours in terms of isolation and anxiety, but there was no significant difference in aggression, and neglect and childish behavior. The results of this study were consistent with some previous studies $[23,30]$ and in contrast with some others [28]. One of the studies that became famous as National Television Violence Study (NTVS) showed that in America: 1. Television violence is often presented in charismatic and exciting ways; 2 . Scenes which are extremely dangerous in terms of learning violence by children under the age of 7 years are shown in specific programs and channels for this age group; and 3. The number of anti-violence programs is not much [21].

Children usually begin watching cartoon videos from the age of 2 years and become accustomed to television at the age of 6 years. Violent television programs not only have a negative impact on children in the short term but also influence their beliefs and values. Displaying power of the cinema stars and the fantasy heroes teach children that everyone with more power is right and people can gain every demand with force. When viewers are focusing on someone else's behavior, they may try to copy that model. But, the important thing to consider is that irrespective of whether the pattern is alive or as a television program (film, cartoon, etc.), the intensity of imitation is the same [31]. Children acquire many of their behavioral patterns, moral attributes, motivations, and attitudes through imitation, identification, and mirroring processes. Identification is an emotional bond between the child and the person identified. Another aspect of the replication is the child's perception of his own similarity to the model and consequently, the acquisition of characteristics and model reactions [32]. In this regard, it is worthy of note that children after viewing animations may imagine them as similar to or far from themselves and in order to become similar to them or to avoid them, most of the time that children watch television is to watch bogus programs. For example, children before the age of 10 years pay less attention to news programs, but youngsters are more interested in cartoons, fantasy heroes and comic situations than other programs. In other words, most of the children's interest is animations and stories. Based on a research [21], animation has the highest percentage of children's interest compared to other television programs (songs, lyrics, poetry, interviews, films, etc.).

There is a relationship between watching television and the rough behaviors of children and teens. The child and family are affected by the culture in which they are living. Apart from home and school, multiple environmental conditions affect the expectations of adults from their children and the expectations of the children themselves. Values and environmental standards are transferred to children through conditions, demands, prohibitions, and various models such as displaying violence in mass media, using horror and force, changing values about sexual behaviors and issues, religious demands and restrictions, etc. Psychologists believe that watching television a lot causes inactive thinking and makes children spend less time for reading, playing, and interacting with others. On this basis, especially, at a younger age, children do not understand much of what they see on television and cannot connect the separate scenes to each other as a story, they only remember a particular disruptive behavior and also show it in their behaviors [33, 34].

Prospective research has shown that children with a high degree of aggressiveness are more enthusiastic about television violence. The more they see these programs, the more they are likely to resort to violence to solve their problems. In addition, many television violence scenes are displayed in the form of a joke, and violence in children's cartoons can lead to aggressive and violent behavior in children and adolescents [33, 34]. Television violence makes children heartless to aggression and makes them more willing to allow aggression towards others [35].

The following items can be mentioned as other findings of this research: there was a significant relationship between watching foreign and Iranian movies with aggression, and neglect and child behaviors. Watching too much television causes isolation and anxiety. Research conducted across the globe suggested that most children consider watching television as one of the daily entertainments in the world. For example, statistics in the United 
States of America have shown that every child watches television on an average for 4 to 5 hours a day, which reaches 10 hours on holidays. Other studies showed that children in lower economic and social levels spend more time watching television. They watch television more than just talking to their parents, playing with their friends, playing sports, and having fun or reading books.

\section{Conclusion}

In general, it seems that decreasing children's television watching can prevent behavioral problems. Based on the results of his study, it is recommended that parents should control the hours spent by their children while watching television, as well as selection of program type (Iranian and foreign). They should provide infrastructure and tools to enrich leisure and entertainment facilities for children's development. The content of Iranian and foreign films and animations should be more focused by parents as children do not learn violent behavior from these films. The results of this study showed that foreign movies and cartoons also have a negative effect on children. Therefore, special attention must be paid to teach the management of hours spent in watching television, as well as selection of appropriate programs (type and content) by parents and education authorities.

Since the role of playing and interacting with peers is very important in learning and reducing inhibitions, there should be more information on the role of kindergartens, especially for children who are single or spend a lot of time at home. This will enable them to spend less time playing video games and watching television, thereby reducing the risk of isolation in children.

The limitations of this study included the difficulty in estimating the approximate time of using television and time of playing with children from parents, the lack of cooperation by some parents to fill out the questionnaires, and the focus of the research on 4- to 6-year-old children.

\section{Acknowledgments}

The paper resulted from a master's thesis presented to the Islamic Azad University. The researchers thank and appreciate the sincere cooperation of preschool children, their parents and preschool authorities.

\section{Conflict of Interest}

The authors declared no conflicts of interest.

\section{References}

[1] Abolhassani SR, Babaei M. [A theoretical approach to the media and politics relations (Persian)]. Political Quarterly. 2012; 42(2):1-22.

[2] Carlsson U, Von Feilitzen C. Children and media violence. Yearbook from the UNESCO international clearinghouse on children and violence on the screen, 1998. Gothenburg: Goteborg University; 1998.

[3] Brown JD, Witherspoon EM. The mass media and American adolescents' health. Journal of Adolescent Health. 2002; 31(6):153-70. doi: 10.1016/s1054-139x(02)00507-4

[4] Hopf WH, Huber GL, Weiß RH. Media violence and youth violence: A 2-year longitudinal study. Journal of Media Psychology. 2008; 20(3):79-96. doi: 10.1027/1864-1105.20.3.79

[5] Whitney C, Wartella E. Violence and Media. In: Wright J., editor. International Encyclopedia of the Social \& Behavioral Sciences. London: Elsevier Science Ltd; 2001.

[6] Molagholamreza Tabasi F, Aliabadi F, Alizade Zarei M, Qorbani M, Rostami R. Survey of behavioral problems and sensory processing in children with attention deficit/hyperactivity disorder. Iranian Rehabilitation Journal. 2016; 14(1):63-8.

[7] Kenway J, Bullen E. Consuming children. Education-Entertainment-Advertising. Buckingham: Open University Press; 2001.

[8] Bandura A. Social learning theory of aggression. Journal of Communication. 1978; 28(3):12-29. doi: $10.1111 /$ j.14602466.1978.tb01621.x

[9] Tannenbaum PH, Zillmann D. Emotional arousal in the facilitation of aggression through communication. Advances in Experimental Social Psychology. 1975; 8:149-92. doi: 10.1016/ s0065-2601(08)60250-6

[10] Krahé B, Möller I, Huesmann LR, Kirwil L, Felber J, Berger A. Desensitization to media violence: Links with habitual media violence exposure, aggressive cognitions, and aggressive behavior. Journal of Personality and Social Psychology. 2011; 100(4):630-46. doi: 10.1037/a0021711

[11] Josephson WL. Television violence and children's aggression: Testing the priming, social script, and disinhibition predictions. Journal of Personality and Social Psychology. 1987; 53(5):882-90. doi: 10.1037// 0022-3514.53.5.882

[12] Aluja-Fabregat A. Personality and curiosity about TV and films violence in adolescents. Personality and Individual Differences. 2000; 29(2):379-92. doi: 10.1016/s01918869(99)00200-7

[13] Gerbner G. Cultivation analysis: An overview. Mass Communication and Society. 1998; 1(3-4):175-94. doi: 10.1080/15205436.1998.9677855

[14] Gerbner, G. Cultural indicators: The case of violence in television drama. Annals of the American Academy of Political Social Science, 1970; 388:69-81.

[15] Crook C. Technology, media, and social development. In: A. Campbell, S. Muncer editors. The Social Child. East Sussex: Psychology Press Ltd. 1998. 189-218.

[16] Khanjani Z, Azimzadeh S. [A Comparative study of the type and amount of aggression among teens exposed to vio- 
lent movies in Meshkinshahr (Persian)]. Woman and Family Studies. 2010; 3(9):81-96.

[17] Hammermeister J, Brock B, Winterstein D, Page R. Life without TV? Cultivation theory and psychosocial health characteristics of television-free individuals and their television-viewing counterparts. Health Communication. 2005; 17(3):253-64. doi: 10.1207/s15327027hc1703_3

[18] Shanahan J, Morgan M. Television and its viewers: Cultivation theory and research. Cambridge: Cambridge University Press; 1999.

[19] Ruggiero TE. Uses and gratifications theory in the $21^{\text {st }}$ century. Mass Communication and Society. 2000; 3(1):3-37. doi: 10.1207/s15327825mcs0301_02

[20] Metani M, Hassanzadeh R, Farhangui AA. [The investigation of Qaemshahr audiance attitude to the satelite TV channels (Persian)]. Culture-Communications Studies. 2013; 14(21):129-56

[21] Moussapoor N, Dor Taj F. [Evaluation of religious animations in the IRIB (Persian)]. Journal of Iran Cultural Research. 2008; 1(3):157-82.

[22] Nejati V. [Epidemiology of behavioural problems in elementary school students of Tehran satellite cities (Persian)] Journal of Medical Council of Iran. 2012; 30(2):162-8.

[23] Özmert E, Toyran M, Yurdakök K. Behavioral correlates of television viewing in primary school children evaluated by the child behavior checklist. Archives of Pediatrics \& Adolescent Medicine. 2002; 156(9):910-4. doi: 10.1001/archpedi.156.9.910

[24] Garvis S, Pendergast D. Warning-television viewing may harm your child's health: Parent perceptions of early childhood viewing habits. Australasian Journal of Early Childhood. 2011;36(4):22-8.

[25] Cuñado J, de Gracia FP. Does education affect happiness? Evidence for Spain. Social Indicators Research. 2012; 108(1):185-96. doi: 10.1007/s11205-011-9874-x

[26] Naghdi Do Robati F. [Studying the relationship between maternal employment and social adaptation of children (Persian)] [MA thesis]. Tehran: Tehran University; 2001.

[27] Esmi R, Sa'idipour E, Assadzadeh H. [The relationship between watching TV commercials and consumption pattern in children and adolescents in Tehran (Persian)]. Communication Research. 2010; 17(1):93-117.

[28] Seyedamini B, Moradi A, Malek A, Ebrahimi-Mamaghani M. [The Role of Watching TV. in Obesity and Behavioral Problems in Children (Persian)]. Iran Journal of Nursing. 2010; 23(67):8-14

[29] Rutter M. A children's behaviour questionnaire for completion by teachers: Preliminary findings. Journal of child Psychology and Psychiatry. 1967; 8(1):1-11. doi: 10.1111/j.14697610.1967.tb02175.x

[30] Wells NM, Lekies KS. Nature and the life course: Pathways from childhood nature experiences to adult environmentalism. Children Youth and Environments. 2006; 16(1):1-24.

[31] Schultz Duwan P, Allen SS. Theories of Personality [Y. Seyed Mohammadi Persian trans]. Tehran: Homa Publications; 2005.
[32] Raheb G, Khaleghi E, Moghanibashi-Mansourieh A, Farhoudian A, Teymouri R. Effectiveness of social work intervention with a systematic approach to improve general health in opioid addicts in addiction treatment centers. Psychology Research and Behavior Management. 2016; 9:309-315. doi: 10.2147/PRBM.S110705

[33] Berk L. Development through the lifespan. London: Pearson Education; 2001

[34] Berk LE. Development through the lifespan, 4/E. Boston: Allyn \& Bacon; 2007.

[35] Donnerstein E, Slaby RG, Eron LD. The mass media and youth aggression. In Eron LD, Gentry JH, Schlegel P, editor. Reason to Hope: A Psychosocial Perspective on Violence \& Youth. Washington, D.C.: American Psychological Association; 1994. 